\title{
LA etNometodología de HaRold Garfinkel en el AULA
}

\author{
The ethNOMETOdology Of HAROLd GARFINKEL IN THE \\ CLASSROOM
}

\author{
Pablo Hermida Lazcano \\ Instituto de Enseñanza Secundaria "El Brocense", Cáceres \\ phermidal@yahoo.com
}

\begin{abstract}
Resumen: Este ensayo parte de una experiencia disruptiva en un aula de bachillerato de un instituto español. En el transcurso de una clase ordinaria de filosofía, un incidente inesperado rompe la definición de la situación, haciendo añicos el consenso de trabajo entre los alumnos y el profesor. Para reconstruir su trasfondo de expectativas, los alumnos se ven forzados a emplear estrategias de acomodación y normalización. En el análisis de esta experiencia disruptiva convergen la fenomenología del mundo social de Alfred Schütz, la etnometodología de Harold Garfinkel y el interaccionismo simbólico de Erving Goffman.
\end{abstract}

Palabras clave: Etnometodología. Experiencia disruptiva. Definición de la situación. Consenso de trabajo. Normalización y acomodación. Manejo de impresiones.

\begin{abstract}
This essay starts from a disruptive experience in a Spanish high school classroom. In the course of an ordinary philosophy lesson, an unexpected incident breaks the definition of the situation, smashing the working consensus among students and teacher to smithereens. In order to rebuild their background expectancies, the pupils are forced to resort to accommodation and normalization strategies. The analysis of this disruptive experience is based upon the convergence of Alfred Schütz's phenomenology of the social world, Harold Garfinkel's ethnomethodology, and Erving Goffman's symbolic interactionism.
\end{abstract}

Keywords: Ethnomethodology. Disruptive experience. Definition of the situation. Working consensus. Normalization and accommodation. Impression management.

\section{ABRECARTAS Y MOLINOS DE VIENTO}

Dictan las convenciones literarias que los baúles que atesoran recuerdos se encuentren en los desvanes. Yo no vivo en una casa con desván, pero a mi piso de ciudad provinciana le corresponde un trastero en los sótanos del edificio. Allí no guardo ningún baúl, pero rescaté una carpeta azul gastada, cuyos múltiples 
rótulos tachados delataban, a modo de cicatrices, los cien oficios que había desempeñado a mi servicio. Al abrirla encontré un abrecartas, unas fotografías y un buen fardo de folios con apuntes y numerosos cuestionarios.

El abrecartas estaba acostumbrado a vivir sobre el escritorio de Alfred Schütz. Era el regalo que me había entregado Lester Embree en Madrid en 2001, cuando aceptó la invitación para formar parte del tribunal ante el que defendí mi tesis doctoral, que no se publicaría hasta catorce años después en México con el título de Relevancias vitales: Alfred Schütz y la filosofía del mundo sociocultural.

Las fotografías las habíamos tomado con su cámara panorámica en los molinos del pequeño pueblo manchego de Campo de Criptana. En una de ellas, aquel niño gigante, mitad Quijote mitad Sancho, aparecía dispuesto a arremeter contra uno de los molinos. Lester había venido a pasar unos días a Alcázar de San Juan, donde yo vivía por aquel entonces. Largas y gozosas fueron nuestras charlas en las treguas de aquella ruta por la Mancha quijotesca que Embree tanto ansiaba explorar. Con el cerro de los molinos de fondo, evocamos juntos el ensayo que Schütz dedicara a «Don Quijote y el problema de la realidad». Entre migas, pistos, duelos y quebrantos, quesos y vinos manchegos, recordamos nuestro primer encuentro unos años atrás en Nueva York, en un seminario sobre Schütz en la New School for Social Research, donde yo estudiaba a la sazón gracias a una beca de la Fundación Barrié. Con su entusiasmo y su pasión habituales, Lester me hablaba de sus proyectos infinitos. Yo le hablaba de mi aterrizaje en la enseñanza secundaria y de mis intentos por trasladar a las aulas de los institutos algo de mi dedicación de aquellos años a la sociofenomenología, la etnometodología o el interaccionismo simbólico. En una de aquellas charlas le enseñé aquellos folios que ahora amarilleaban en mi carpeta azul. Le conté que eran mis notas y los cuestionarios de mis alumnos sobre un pequeño experimento en las aulas del instituto de Guadalajara donde había debutado como profesor de filosofía. Tras escuchar con interés mi relato y bombardearme con sus preguntas, me sugirió la posibilidad de contar por escrito aquella modesta experiencia disruptiva. Solo he tardado veinte años en hacerlo.

\section{UNA EXPERIENCIA DISRUPTIVA EN EL AULA}

El investigador que se propone entender en qué consiste el orden social y cómo logran mantenerse las instituciones sociales, se topa con el inconveniente 
de que los cimientos sobre los que parecen sustentarse nuestras prácticas e interacciones cotidianas (el acervo de conocimiento, el trasfondo de expectativas, el consenso de trabajo en la común definición de la situación) son demasiado vaporosos e imperceptibles. Por este motivo, el sociólogo estadounidense Harold Garfinkel, discípulo de Schütz y fundador de la corriente conocida como etnometodología, tuvo la feliz ocurrencia de reflexionar sobre la vida social normal dando un rodeo estratégico por situaciones anómalas o anormales. Esa vida social normal, cuyos cimientos y fundamentos quería poner de manifiesto Garfinkel, es lo que Dewey denomina mundo del sentido común, que entronca con el mundo de la vida de Husserl y el mundo de la vida cotidiana de Schütz. La estrategia de Garfinkel consistía en llevar a cabo una serie de «experiencias disruptivas», creando artificialmente situaciones problemáticas que hiciesen tambalearse todos esos pilares que parecen soportar la realidad social cotidiana. Estaba convencido de que tales experiencias «habrían de decirnos algo sobre el modo como se mantienen rutinaria y ordinariamente las estructuras sociales».

Pues bien, siguiendo la pista de Garfinkel, yo me preguntaba qué ocurriría si, de repente, en un establecimiento social como un aula de bachillerato de un instituto, un incidente inesperado rompiese brutalmente la definición de la situación imperante, haciendo añicos el consenso de trabajo entre alumnado y profesor y reventando así el trasfondo de expectativas de los alumnos.

Para ejecutar mi maquiavélico plan necesitaba ayuda, y tuve la fortuna de encontrarla en el entusiasmo y el talento interpretativo de Lucas, que se esmeró en la representación de «la rebelión del buen alumno». Subrayo lo de «buen alumno», porque aquí es donde el ataque a las expectativas del resto del alumnado comenzó a surtir efecto. A continuación pasaré sucinta revista a los aspectos de aquel episodio que, según atestiguan los cuestionarios respondidos por los alumnos, contradecían de forma más flagrante sus expectativas en función de la definición de la situación: «clases de filosofía con el profesor X».

La primera tarea del cuestionario consistía simplemente en relatar los hechos vividos. Este es el relato de Raquel, una alumna del grupo:

Como de costumbre, un viernes más a las diez y media toca filosofía. Mientras apuramos los minutos que siguen al timbre de entrada, llega Pablo, el profesor. Nos 
agolpamos en la puerta para entrar y en breves instantes ocupamos nuestros sitios. Algunos no han llegado todavía del recreo y hay varios sitios vacíos. El profesor pregunta por qué falta tanta gente y nadie responde. Pronto nos percatamos de que el profesor no viene de muy buen humor. Nos dice que tiene un «insoportable dolor de cabeza», y su humor empeora con la llegada desordenada de los ocupantes de los sitios vacíos. Aunque nos cuesta concentrarnos, el profesor logra retomar el tema de la sociología comenzado el día anterior. Todos escuchamos más o menos atentos para pillar algo importante que apuntar en nuestros cuadernos.

De repente, cuando pasan casi quince minutos de las diez y media, se abre la puerta de clase. Todos miramos, incluido el profesor. Aparece Lucas con un fuerte jadeo, que a todos nos induce a pensar que viene corriendo de algún sitio. Sin llamar, entra en clase esquivando al profesor y se sienta. Todos miramos asombrados por su falta de educación, esperamos la reacción de Pablo y, al mismo tiempo, nos ponemos en el lugar de Lucas, temerosos de lo que se le vendría encima tras un gesto tan imprudente por su parte. El profesor le mira atónito y le pregunta si no le han enseñado a llamar. Lucas le devuelve la mirada, pero no le responde. A partir de ahí, se enzarzan en una acalorada discusión. El profesor le pide que salga, llame a la puerta y pregunte si puede entrar. Lucas llega a la puerta en dos zancadas, exclama un sonoro «ijoder!» y sale pegando un gran portazo. Llama, abre la puerta de nuevo y con tono burlón pregunta si se puede. El profesor le niega la entrada alegando que es demasiado tarde y Lucas protesta: «¿Me tienes haciendo el gilipollas para hacer la gracia?»

Todo parecía real, los dos se mostraban nerviosos. El profesor insistió en que saliera de clase, esta vez con un tono más grave, pero Lucas se resistía. El profesor trataba de defender su campo como podía. Entonces Lucas propuso ir a ver a la jefa de estudios y Pablo sugirió acudir mejor al director. Todos conocíamos la mala relación que nuestro profesor tenía con ambos. Lucas accedió intentando disimular el pánico y aparentando ser fuerte ante los demás, que contemplábamos con asombro lo que podía ser ya el irremediable fin de su historia en el instituto. Pablo nos señaló un texto que debíamos leer durante su ausencia. Salieron y la clase fue un murmullo. Todos comentábamos entre nosotros la imprudencia de Lucas al enfrentarse al profesor de esa manera tan agresiva, sabiendo que no tenía razón y que era Pablo quien llevaba todas las de ganar. Vuelve Lucas y poco después Pablo, quien prosigue la clase bastante alterado, incluso con ira en su mirada, y aprovechando cualquier ocasión para castigar a Lucas con sus reproches y comentarios hirientes, incluso sugiriendo que Lucas había estado fumando porros antes de venir a clase.

La cosa se fue calmando hasta que llegamos a una parte de la sesión en la que se hablaba de la metáfora teatral. Llegados a este punto, nos desvelaron la broma de la que habíamos sido víctimas. Se trataba de una farsa y todos nos sentimos frustrados por nuestra atrofiada intuición, que no nos dejó percatarnos de que aquello era simplemente teatro. 
En efecto, casi todos sus compañeros tenían a Lucas por lo que habitualmente se entiende por un buen alumno, esto es, no solo con un satisfactorio rendimiento académico, sino también -lo que resulta más relevante en nuestro contexto- un alumno respetuoso con los profesores o, al menos, con el profesor X. Por otra parte, en el acervo de conocimiento compartido por los muchachos constaba la alta probabilidad de que Lucas consolidase su buena calificación en la materia y, en general, culminase airosamente sus años de permanencia en el instituto. A este elogioso retrato de Lucas solían incorporar los atributos de cordura, sensatez y capacidad de diálogo y razonamiento. Incluso quienes reconocían en Lucas una cierta impulsividad, se resistían a tipificarle como uno de esos individuos capaces de tirarlo todo por la borda en un segundo. Pues bien, desde el primer momento, el comportamiento de Lucas amenazaba con hacer añicos el manojo compartido de expectativas sobre él: desde sus modales y su tono de voz hasta su terquedad y obstinación, pasando por la falta de prudencia y la ceguera suicida, que parecían arrastrarle hacia su perdición académica. Todo ello, al fin y al cabo, por «tan poca cosa» y encima, según confesaban muchos, con casi toda la razón en su contra. ¿Qué demonios le estaba ocurriendo a Lucas?

Por lo que se refiere al profesor $X$, su comportamiento no se les antojó, por lo general, excesivamente extraño (lo que he de confesar que no resultaba muy halagador para mí y me dio mucho que pensar). Casi todo lo que el profesor hizo y dijo parecía encajar en las expectativas del rol de profesor que tenían sus alumnos. Ello demuestra que, en su tipificación del papel de profesor, tienen cabida ingredientes tales como la necesidad de hacerse respetar y de imponer su autoridad (a gritos, si llega el caso) ante cualquier desafío o intento de sublevación por parte del alumnado. Felizmente, algunos ponían en duda que entre las competencias del rol de profesor figurase la humillación pública de su alumno, por más que a veces les pareciera justificable, cuando se trataba de «legítima defensa» ante la humillante ofensiva del estudiante.

Lo que estaba haciendo Lucas con su magistral interpretación consistía precisamente en hacer explotar ante sus compañeros ese pacto tácito que nos mantenía vinculados y organizados a diario en esa pequeña institución u orden social que es la clase. En términos de Erving Goffman, Lucas estaba rompiendo brutalmente el consenso de trabajo, desafiando el sentido y la confianza comúnmente otorgados a la realidad del aula, invitando a sus compañeros a rechazar la defi- 
nición de la situación imperante al cuestionar o tornar problemáticos los presupuestos sobre los que se asentaba y funcionaba día tras día, sin grandes traumas, aquel micro-orden social e institucional.

Para retratar el desolado paisaje emergido tras la explosión del trasfondo de expectativas del alumnado, nada mejor que sus propias declaraciones plasmadas en los cuestionarios. En pocas de ellas falta la alusión a la tensión, la perplejidad e incluso, muy a menudo, el miedo, la angustia y la ansiedad que experimentaron. Tales descripciones apuntan hacia el cuadro ideal de reacciones y consecuencias pronosticadas por Garfinkel para experiencias disruptivas en situaciones límite: «En términos ideales, los comportamientos dirigidos hacia semejante entorno carente de sentido deberían caracterizarse por el desconcierto o la perplejidad, la incertidumbre, el conflicto interno, el aislamiento psicosocial y una indecible ansiedad, junto con varios síntomas de despersonalización aguda. Todo ello acompañado de la correspondiente desorganización de las estructuras de interacción».

En este punto se hace precisa una importante observación. Según Garfinkel, el éxito al crear la deseada confusión en los sujetos mediante una experiencia disruptiva depende de la satisfacción de tres condiciones: «que la persona no pueda interpretar la situación como un juego, una escenificación, una broma, un experimento, un engaño o algo similar, esto es..., que no pueda "salirse del terreno"; que no disponga del tiempo suficiente para elaborar una redefinición de sus circunstancias reales; y que se vea privada de un soporte consensuado para una definición alternativa de la realidad social». Pues bien, estas tres condiciones pudieron verse un tanto amenazadas aquel fatídico viernes. Por un lado, la sospecha de que podía tratarse de una farsa rondaba por las cabezas de algunos alumnos, pues ya en otras ocasiones el profesor $X$ les había tomado el pelo. Pero la principal amenaza al trío de condiciones apuntadas dimanaba de una variante introducida en aquella experiencia, que la diferenciaba de la mayoría de las diseñadas por Garfinkel. Me refiero al breve lapso en que Lucas y yo salimos del aula, so pretexto de acudir a dirección o a jefatura de estudios, brindando a los alumnos una pequeña oportunidad de fabricar, tanto individual como concertadamente, una redefinición de la situación. Bien es verdad, sin embargo, que la brevedad de nuestra ausencia les impedía consensuar con suficiente rigor una definición alternativa de la realidad y ponderar en sus justos términos el posible 
alcance de los recientes acontecimientos. De hecho, no lograron ir más allá de meros esbozos o tentativas de reconstrucción.

Esto nos conduce a un aspecto crucial para las pretensiones teóricas de Garfinkel. Me refiero a lo que este autor denomina normalización y acomodación. Con tales rótulos, Garfinkel se refiere a los procesos y las operaciones mentales y conversacionales de ajuste llevados a cabo por las personas con el fin de restaurar el sentido y la estructura de su realidad, amenazados por incongruencias, contradicciones, sinsentidos y quiebras de expectativas, tal y como acontece tras una «experiencia disruptiva». Todos nos afanamos en restaurar el orden natural de las cosas desterrando la sombra amenazadora y espeluznante del caos, intentando reactivar la fuerza de lo típico, lo probable, lo esperable, lo comparable. Y gracias a estos esfuerzos normalizadores, todos contribuimos a que nuestro mundo social siga siendo una realidad más o menos ordenada, organizada, estructurada, estable... institucionalizada.

En la experiencia que estoy describiendo, constatamos sugerentes ilustraciones de estas tácticas de reajuste, normalización y acomodación. Así, unos y otros intentaban conferir un sentido a la incongruente y desconcertante actuación de Lucas, para lo cual hacían conjeturas y elucubraciones sobre lo que podía haberle ocurrido antes de la clase, y que justificaría o al menos tornaría comprensibles sus presentes reacciones. En este sentido, a partir de la escasa información alegada por Lucas a modo de excusa por su tardanza, y partiendo de la base de que «desde luego Lucas no es así», sus compañeros construían inductivamente inferencias del estilo de «Lucas viene sofocado de la biblioteca. Le habrán entretenido más de la cuenta o habrá tenido algún incidente o encuentro desafortunado en el camino»; «la cosa ha empezado a lo tonto, por una chorrada, y ahora no es capaz de dar marcha atrás»; «parece que quiere hacerse el gallito delante del resto de la clase»; «se lleva tan bien con el profesor que ya no es capaz de distinguir entre el trato dentro y fuera del aula», etc. Por su parte, los esfuerzos normalizadores con respecto a cuanto de sorprendente pudiese haber en la actuación del profesor se basaban en una doble estrategia. En primer lugar, los alumnos explotaban al máximo la alusión del profesor a su dolor de cabeza al comienzo de la clase, lo que explicaría tanto su rostro canino como su reacción desmesurada contra Lucas. La segunda estrategia de acomodación estribaba en justificar reacciones que se les antojaban desorbitadas tratándose del profesor 
$\mathrm{X}$, remitiéndolas a sus expectativas del rol de profesor en general, en virtud de las cuales ninguna reacción parecía francamente tan descabellada.

Acabo de aludir a la elaboración de inferencias. Y es que, como afirma W. I. Thomas y nos recuerda Goffman, en el mundo social «vivimos por inferencia», completando aventuradamente por nuestra cuenta y riesgo los datos, con frecuencia escasos y no siempre sinceros ni verídicos, que obtenemos en nuestras interacciones con los otros. Goffman traza una distinción entre las expresiones que el individuo da o transmite (gives) de una forma controlada y las expresiones emanadas (given off) de la persona de forma involuntaria o inconsciente, cual si de un torrente de signos se tratase. Cabría analizar cuánto de transmisión y cuánto de catarata sígnica hubo en las actuaciones de Lucas y del profesor. Ello permitiría ilustrar el rico examen de Goffman sobre el manejo de impresiones (impression management). A título de ejemplo, en sus finos y agudos comentarios, los alumnos reparaban en cosas tan sutiles como la risa nerviosa de Lucas o la forma en que el profesor apretaba las mandíbulas.

Conviene señalar que este tipo de análisis microsociológico debería ser complementado con una aproximación macrosociológica, que diese cuenta de las grandes estructuras, instituciones y procesos sociales, así como del modo en que estos predeterminan toda interacción cotidiana, como un incidente disciplinario en una clase de filosofía de un instituto cualquiera un viernes cualquiera. Huelga decir que el modo como definimos conjuntamente la situación «clase de filosofía de bachillerato con el profesor $X »$, la forma en que los alumnos $y$ el profesor conciben y desempeñan sus roles respectivos, se hallan profundamente condicionados por circunstancias y factores históricos, políticos, económicos e ideológicos: desde la historia de sistema educativo español hasta la última reforma educativa, pasando por las inversiones en educación, las relaciones entre enseñanza pública y privada, los modelos de autoridad en las sociedades occidentales contemporáneas, los valores éticos y religiosos vigentes, la distribución de funciones educativas entre familia y escuela, el poderoso influjo de esos otros profesores que son los medios de comunicación y las redes sociales, los vínculos entre educación y mercado, y suma y sigue.

\section{LAS ESTRUCTURAS DEL MUNDO SOCIAL}

Nuestras interacciones cotidianas se llevan a cabo sobre la base de un considerable repertorio de presupuestos, cosas dadas por sentadas, elementos in- 
cuestionados. Bajo el rótulo de mundo incuestionado, dado por sentado o presupuesto, autores como Alfred Schütz o sus discípulos Peter Berger y Thomas Luckmann aluden a esa infinidad de detalles intersubjetivamente compartidos en los que apenas solemos reparar y que, sin embargo, constituyen los cimientos sobre los que se edifica, se sostiene y funciona nuestra realidad social. Este conjunto de presupuestos es el que nos ayuda, en cada caso, a «ponernos en situación». Este «ponerse en situación» en cada caso para saber lo que podemos esperar, cómo podemos o debemos comportarnos y hasta dónde podemos llegar en cada encuentro o interacción social, es lo que se conoce como definición de la situación, término clave de la microsociología, manejado con particular entusiasmo por la escuela conocida como interaccionismo simbólico que, arrancando en G. H. Mead, encuentra en Blumer, Goffman y Turner a sus más ilustres representantes.

Un ingrediente fundamental en cada una de nuestras definiciones de la situación lo constituye el cálculo recíproco de expectativas, esto es, el conjunto de lo que yo espero de los otros y los otros esperan de mí y de mi comportamiento, en función tanto de los individuos singulares que somos (expectativas personales o individuales) como de los roles o papeles que desempeñamos en la situación social en que unos y otros nos hallamos (expectativas de rol). En este sentido, como afirma Goffman, los miembros de un equipo de actuantes cooperan para presentar al auditorio una determinada definición de la situación. Así, por ejemplo, los integrantes de un claustro de profesores de un instituto intentarán alcanzar unos acuerdos básicos sobre el modo de definir ante el auditorio de alumnos el día a día del centro, las coordenadas que deben definir las interacciones entre alumnos, profesores, equipo directivo, etc. A su vez, cada profesor particular intentará imponer en sus clases una determinada definición de la situación: los coeficientes de autoridad, poder, jovialidad, cercanía o lejanía, grados y formas de participación, tolerancia para con las faltas de puntualidad, las distracciones, los despistes, los ruidos y demás tentativas de sabotaje. En definitiva, la tónica que ha de gobernar sus clases, la definición de lo que sus clases son o deberían ser. Por su parte, los estudiantes harán cuanto esté en sus manos por imponer sus propias definiciones de la situación o, al menos, influir en cada una de ellas. Con este fin podrán valerse tanto de los mecanismos legales y formales de participación (asambleas, delegados, representantes en el Consejo Escolar) como 
de la negociación continua ante los otros equipos (profesores, equipo directivo) a través de gestos, actitudes, pulsos y acciones simbólicas.

Una vez establecidas las líneas básicas de una determinada definición de la situación, muchos de sus ingredientes sufrirán un proceso paulatino de rutinización o habitualización, sedimentándose hasta formar parte del acervo de conocimiento, esto es, del repertorio de conocimientos y experiencias socialmente compartidos por los miembros del grupo en cuestión.

Así, por ejemplo, en el acervo de conocimiento compartido por los estudiantes y el profesor que subyace a la definición de la situación «clase ordinaria de filosofía con el profesor $X »$, ocupan un lugar privilegiado datos como los siguientes: expectativas de los alumnos de bachillerato con respecto a los profesores de su instituto, fruto de sus experiencias acumuladas durante varios años de permanencia en el centro; expectativas con respecto al profesor de filosofía y sus clases, tras varios meses de participación en ellas; expectativas con respecto al individuo $X$ que desempeña el rol de profesor de filosofía, fruto del conocimiento personal dentro y fuera del instituto, en la vida académica y extraacadémica; recíprocamente, expectativas del profesor $X$ con respecto a sus alumnos de bachillerato, tanto las concernientes al grupo como a cada estudiante en particular, incluido Lucas. Asimismo existen expectativas de cada alumno con respecto al resto de sus compañeros de clase, entre ellos Lucas, fruto de su mayor o menor conocimiento y relación. Al acervo de conocimiento intersubjetivamente compartido pertenece, además, todo cuanto se sabe, se presupone y se espera sobre aspectos formales y organizativos de la vida del instituto: duración de las clases, relaciones de autoridad, existencia de un director y un jefe de estudios con unas funciones más o menos determinadas, etc.

Por supuesto, más allá del acervo de conocimiento comúnmente compartido, existe una distribución social del conocimiento, dependiente de la situación biográfica de cada persona (por ejemplo, distintos grados de intimidad con Lucas) y de la división social del trabajo (los alumnos saben cosas sobre la clase que el profesor ignora, y viceversa; los representantes en el Consejo Escolar poseen conocimientos teóricos y prácticos sobre sanciones que sus compañeros desconocen). Obviamente, esta variabilidad de conocimientos repercutirá en la precisión de las expectativas creadas sobre los actores y las situaciones, y condicionará asimismo el grado de estupor generado al quebrarse tales expectativas. Veamos algunos ejemplos: 
- Quienes se declaraban amigos íntimos de Lucas confesaron, por lo general, una mayor implicación y turbación durante la escena, así como una mayor perplejidad ante las reacciones de su amigo, tan alejadas de las conductas esperables de alguien a quien pensaban conocer tan a fondo.

- Los representantes en el Consejo Escolar no tardaron en conectar la escena con las sanciones disciplinarias a otros alumnos de las que habían tenido noticia reciente, por lo que su vaticinio sobre el futuro académico de Lucas pudo cobrar un perfil más concreto y sombrío.

- Varios de los alumnos que habían participado en un reciente viaje por Francia y Países Bajos, acompañados por el profesor $\mathrm{X}$, conectaron los acontecimientos del aula con una tristemente memorable noche de desenfreno en Barcelona, en la que el profesor se había visto forzado a mostrar su rostro más temible.

- En cambio, otros que vivieron toda la escena «con la mosca detrás de la oreja» achacaban su predisposición a la incredulidad a lo mucho que el profesor parecía complacerse en tomarles el pelo de vez en cuando.

- Finalmente, al calibrar las consecuencias de la presunta visita de Lucas y el profesor a los miembros del equipo directivo, muchos tuvieron presentes ciertos incidentes acaecidos unos meses atrás, que habían enturbiado las relaciones entre el profesor y sus superiores jerárquicos.

En cualquier caso, más allá de las variaciones individuales, los meses de convivencia dentro y fuera del aula nos habían permitido elaborar conjuntamente una definición de la situación «clase ordinaria de filosofía», sustentada por ese acervo de conocimiento compartido. Conviene insistir en que los múltiples ingredientes que componen dicho acervo de conocimientos y experiencias no han de ser rememorados o reactivados a cada paso. Antes bien, su efectividad para el mantenimiento de nuestra pequeña realidad social del aula estribaba justamente en su carácter rutinizado, habitualizado, sedimentado, casi automatizado. En 
este sentido, si el curso de filosofía podía irse desarrollando con relativa normalidad cuatro horas semanales durante varios meses, ello se debía a que, desde que empezaba la clase, tanto los alumnos como el profesor daban por sentadas cosas tales como las siguientes: que la clase se impartiría en castellano y en un registro no excesivamente técnico; que los contenidos estudiados tendrían que ver más con las ciencias humanas y sociales que con la mecánica cuántica; que no era preciso, pero tampoco imposible, asistir a clase en ropa de deporte; que era altamente improbable que el director o la jefa de estudios irrumpiesen para bailar un mambo; que no era prudente sacar en mitad de la clase una tortilla de patata y una bota de vino o, finalmente, que alumnos y profesor se presentarían en el aula más o menos a la hora establecida, salvo motivos de fuerza mayor. Precisamente el carácter incuestionado y rutinizado de todas estas presuposiciones las torna tanto más imperceptibles. Ahora bien, por más desapercibidas que nos pasen todas estas pequeñas complicidades, a ellas se debe en buena medida la posibilidad de que existan, se mantengan y funcionen todas nuestras organizaciones o instituciones sociales, incluida esa minúscula parcela de la realidad social que es nuestro curso de filosofía.

Y es que, ciertamente, como Goffman nos recuerda, en condiciones normales las definiciones de la situación proyectadas por los diferentes participantes en una interacción social tienden a armonizarse, esto es, a compatibilizarse unas con otras, apuntando a la postre hacia una sola definición total de la situación. De no ser así, de no existir ese mínimo acuerdo para respetar en lo esencial unas reglas de juego básicas en la definición de cada situación social -acuerdo al que Goffman se refiere como consenso de trabajo-, ninguna institución social se tendría en pie. Las clases de filosofía serían inviables si el profesor hablase cada día un idioma distinto, los alumnos llegasen escalonadamente cada dos o tres minutos, y alguien se levantase de vez en cuando para proclamar «iMuerte al profesor dictador!».

\section{LA ALEGORÍA TEATRAL Y SUS LÍMITES}

Vivir en sociedad es vivir con los otros y ante los otros. Nos presentamos ante otros y ellos se presentan ante nosotros. Una vez que estamos así, yo plantado ante ti y tú ante mí, empezamos a actuar. Y actuar es tanto hablar como 
guardar silencio, hacer como dejar de hacer, moverse como estar quieto, construir o destruir. Y, claro está, actuar es también lo que hacen los actores y actrices sobre el escenario de un teatro. Por ello, la alegoría dramatúrgica en las ciencias sociales está servida.

Cierto es que aquel viernes Lucas y yo estábamos actuando, interpretando papeles ante el inadvertido público de alumnos. Pero cacaso no es eso lo mismo que hacíamos cualquier otro día jugando a alumnos y profesores, al igual que los niños pequeños juegan a los médicos o a papás y a mamás? No obstante, el propio Erving Goffman, maestro en el arte de metaforizar teatralmente lo social, reconoció que el teatro difiere de la vida al menos en (1) la precisión con que han sido ensayadas las representaciones y (2) la presencia de un público, testigo ajeno a la escenificación.

Sobre (1): Es verdad que la precisión de los ensayos teatrales carece de parangón en la vida real, eminentemente espontánea e improvisada. Pero tampoco exageremos: ¿Acaso no preparan los profesores sus clases y los políticos sus intervenciones? ¿Acaso no fabrica mentalmente el empleado su conversación con el jefe cuando se dispone a pedirle un aumento de sueldo, o el feligrés su plática con el señor cura cuando acude a confesarle sus pecados? ¿Acaso no preparamos nuestra indumentaria para la ocasión antes de salir de casa para reunirnos con alguien?

Por otra parte, Lucas y yo casi no habíamos preparado aquella escena. Nuestra preparación apenas se limitó a unos minutos de recreo en los que habíamos bosquejado vagamente la situación: «Entras tarde y sin llamar, te pediré que salgas, llames a la puerta y pidas permiso para entrar, y luego empezaremos a discutir». Unas acotaciones tan precarias como las que caracterizan una infinidad de situaciones cotidianas: «Cuando vayas a revisar el examen, por una vocecita quejumbrosa y verás cómo se le ablanda el corazón a la profe y te sube la nota»; «Cuando vayas a pedir el aumento de sueldo, no te olvides de preguntarle por sus niños y por sus periquitos»; «vamos a ignorarles para que se den cuenta de que están de más».

Cierto es que no vamos por la vida con el guión memorizado, pero no menos cierto resulta que no andamos por el mundo a tontas y a locas. Nuestras andanzas cotidianas suelen estar fuertemente marcadas por cálculos, planes, estrategias y proyectos; en definitiva, por ensayos que preceden habitualmente cada puesta en escena, cada entrada en la arena de lo social. No en vano, al describir 
los planes y proyectos mentales que anteceden normalmente a nuestras acciones, el pragmatista estadounidense John Dewey hablaba de dramatic rehearsals in imagination (ensayos teatrales en la imaginación). Solemos anticiparnos en nuestra mente representando imaginativamente, a modo de ensayo, lo que luego representaremos en la vida real.

Sobre (2): El segundo punto débil de la alegoría escénica subrayado por Goffman estriba en la diferencia entre el esquema teatral tripartito (actor, otros copartícipes y público) y la vida real donde los otros actores y el público se funden, es decir, donde no existe algo así como un auditorio ajeno a la escena representada. A este respecto, cabe preguntarse si, durante el incidente entre Lucas y el profesor, el resto de los alumnos estaban siendo copartícipes, público o ambas cosas a un tiempo. Al revisar sus cuestionarios se constata, cuando menos, preocupación real por las eventuales repercusiones para Lucas. Pero también confiesan con frecuencia miedo a hacer gestos o comentarios que pudieran influir negativamente en la situación, así como temores acerca del giro que podrían experimentar en el futuro las clases de filosofía. Por otro lado, a varios alumnos les parecía necesario que el profesor actuase de forma ejemplarizante ante el resto del alumnado, no tolerando en público ciertos comportamientos de Lucas que podrían sentar fatales precedentes, precisamente porque Lucas podría ser mañana cualquier otro miembro del auditorio. En suma, todos parecían sentirse directa o indirectamente partícipes de la escena, aunque solo fuese por temor a que la ira del profesor se desviase hacia ellos tras alguna extraña mueca.

Desde luego, tampoco faltaban razones para que los alumnos se considerasen espectadores de algo que Lucas y el profesor habían tramado a sus espaldas, en una región posterior (back region) o trasfondo escénico (backstage). Lucas y el profesor formaban un equipo de actuantes que irrumpía ante ellos en el espacio escénico del aula, convertida en región anterior (front region), lugar de presentación ante la audiencia integrada por todos ellos. Pues bien, también el continuo salto entre regiones anteriores y posteriores en un establecimiento social es el pan nuestro de cada día en el mundo social. Así, las clases de un profesor suponen trasladar a la región anterior del aula innumerables decisiones adoptadas en regiones posteriores: reuniones de departamento, claustros, charlas informales con sus colegas. Asimismo, las tertulias en los pasillos o en el patio, así como las horas de estudio en sus habitaciones sirven a los alumnos de regiones posteriores 
en las que preparar las actitudes individuales y grupales que trasladan a la región anterior del aula.

\section{EPÍLOGO EN MARCHA}

El tren cubría su trayecto habitual entre Nueva York y New Haven. Minutos después de abandonar la Grand Central Station, el revisor iniciaba su tarea de control. Chocante resultaba ya el saludo con que aquel negro corpulento acompasaba su taladrar de billetes. Dirigía a cada pasajero un entusiasmado y afectuoso «Buenos días, ¿qué tal se encuentra usted hoy?», cual si de viejos conocidos se tratase. Pero lo verdaderamente sorprendente llegó cuando, una vez consumado su agujereo, se situó en la cabecera del vagón y comenzó a emitir un prolijo parte meteorológico, imitando a los más talentosos locutores de radio o televisión. Todos los vientos, nubes, borrascas, anticiclones, marejadas y cielos despejados fueron invocados en aquella magistral escenificación, coronada por una graciosa reverencia mientras su autor sentenciaba: «Este ha sido nuestro pronóstico meteorológico para las próximas horas».

Creo que aquel hombre me enseñó tanto como el ilustre profesor Natanson a cuyos seminarios en Yale acudía mensualmente en ese tren. Aprendí de aquel entrañable tipo que, sin cesar de desempeñar con dignidad tus papeles, es saludable no dejarse encarcelar ni agotar por ellos. Aprendí que solo si los roles dejaban de ser jaulas para convertirse en pistas de baile podía uno empezar a hacer de su vida algo semejante a una obra de arte. También aquella mañana manchega, plantados los dos ante los molinos de viento y tanteando la manera de arremeter contra sus aspas, compartí con Lester Embree esa sensación de aventura inacabada.

\section{BiBLIOGRAFÍA}

BERGER, Peter L. y Luckmann, Thomas. The Social Construction of Reality; A Treatise in the Sociology of Knowledge, Doubleday, Garden City, Nueva York, 1966 (trad. cast.: La construcción social de la realidad, Buenos Aires: Amorrortu, 19847.)

Garfinkel, Harold. The Perception of the Other: A Study in Social Order, Tesis doctoral inédita, Harvard, 1952. 
-, "A Conception of, and Experiments with, 'Trust' as a Condition of Stable Concerted Actions", en D. J. Harvey (ed.), Motivation and Social Interaction, New York: The Ronald Press Company, 1963.

- $\quad$ "Studies on the Routine Grounds of Everyday Activities", en Sudnow, D. (ed.),Studies in Social Interaction, New York: Free Press, 1972, pp. 130.

-, "When is Phenomenology Sociological?", Annals of Phenomenological Sociology,vol. 2 (1977) 1-40.

—, Studies in Ethnomethodology, Cambridge, MA: Polity Press, 1967.

GoffMAN, Erving. The Presentation of Self in Everyday Life, New York: Doubleday, 1959 (trad. cast.: La presentación de la persona en la vida cotidiana, Amorrortu, Buenos Aires, 2009).

Hermida Lazcano, Pablo. Relevancias vitales: Alfred Schütz y la filosofía del mundo sociocultural, Morelia: Jitanjáfora Morelia Editorial, 2015.

MEAD, George H. Mind, Self, and Society (From the Standpoint of a Social Behaviorist), Chicago: The University of Chicago Press, 1934 (trad. cast.: Espíritu, persona y sociedad desde el punto de vista del conductismo social, Barcelona, Paidós, 1993).

SchüTZ, Alfred. Der sinnhafte Aufbau der sozialen Welt, Suhrkamp, Fráncfort, 1991 (1a ed.Viena: Julius Springer, 1932) (trad. cast.: La construcción significativa del mundo social, Barcelona: Paidós, 1993).

-, Collected Papers II: Studies in Social Theory, ed. Arvid Broderson, The hague: Martinus Nijhoff (trad. cast.: Estudios sobre teoría social, Buenos Aires: Amorrortu, 1974).

SchüTZ, Alfred / LuCKMANN, Thomas. The Structures of the Life World I, Evanston: Northwestern University Press, 1973 (trad. cast.: Las estructuras del mundo de la vida, Buenos Aires: Amorrortu, 1977).

-, The Structures of the Life World II, Evanston: Northwestern University Press, 1989. 


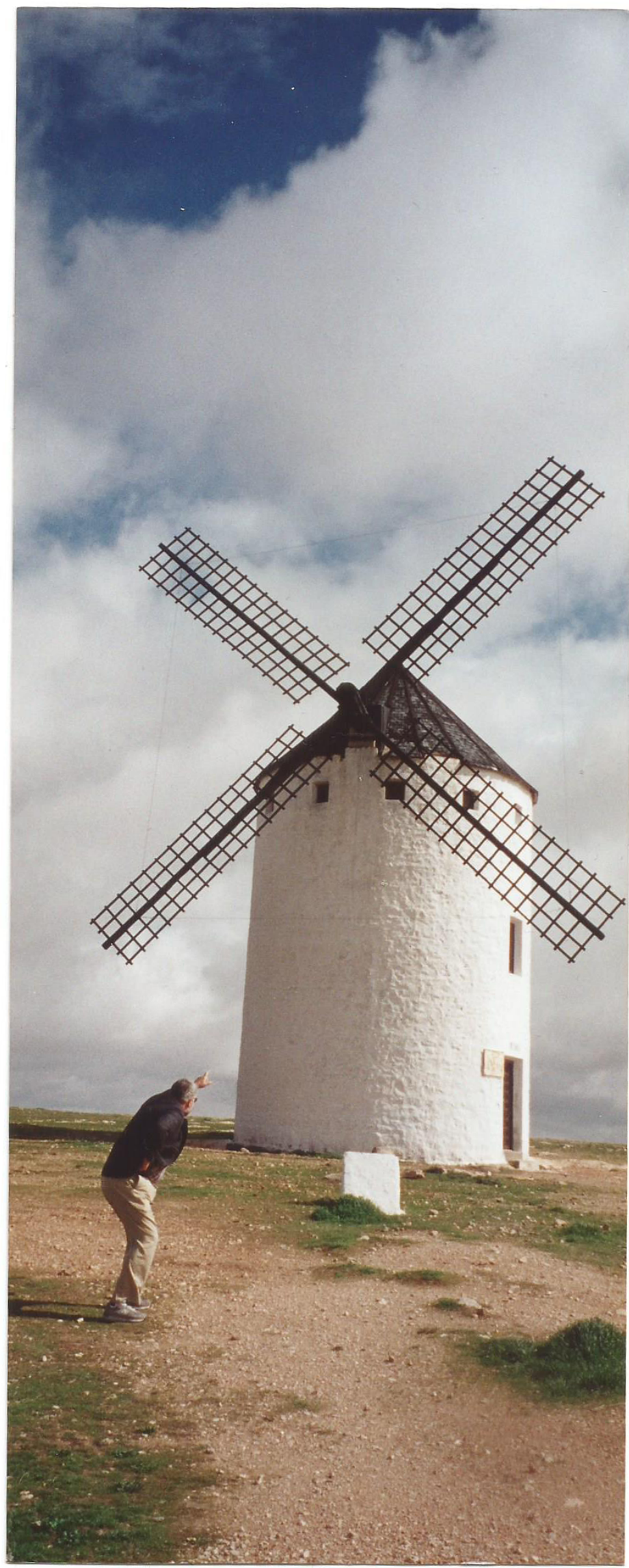

